\title{
How Should Unemployment Benefits Respond to the Business Cycle?
}

\author{
Michael T. Kiley ${ }^{*}$
}

September 2002

Version 1.3

\footnotetext{
"Address: While on Leave (September 2001-August 2003)—OECD Economics Department CS1, 2 rue Andre Pascal, 75016 Paris FRANCE. Email: Michael.Kiley@oecd.org. Permanent Address: Mail Stop 67, Federal Reserve Board, Washington, DC 20551. Email: mkiley@ frb.gov.

Acknowledgements: I would like seminar participants at INSEAD and colleagues at the Federal Reserve Board and the OECD for discussions involving this research and Laura Veldkamp, Alan Krueger, and two anonymous referees for commenting on previous versions of this paper. The views expressed herein are those of the author, and do not represent those of the OECD, the Federal Reserve Board, or their respective
} staffs. 


\title{
How Should Unemployment Benefits Respond to the Business Cycle?
}

\begin{abstract}
Unemployment insurance programs balance the benefits of consumption smoothing for unemployed workers against the disincentive effects of unemployment benefits. Such a balancing of benefits and costs is likely sensitive to the cyclical state of the economy, and hence the generosity of benefits should also respond to the cyclical state of the economy. The nature of such responses in an optimal unemployment insurance (UI) program is analyzed in a simple model. The results suggest that an optimal UI program would increase the initial level of benefits and probably extend higher benefits over time in response to a recessionary shock. A simple extension of benefits, such as exists automatically in the system in the United States, provides both poorer insurance and poorer incentives than the optimal program, and does so at a higher cost. Moreover, the current UI system in the U.S. provides a substantially higher level of welfare to workers who lose jobs during tight labor markets.
\end{abstract}

JEL Codes: E24, J65, J64

Keywords: Unemployment Insurance, Time-Varying Benefits 


\section{Introduction}

Unemployment insurance programs have been designed, at least to some extent, to balance the benefits regarding consumption smoothing for unemployed workers who cannot self-insure against the disincentive effects of unemployment benefits on labor market search and the willingness of the unemployed to accept job offers. Such a balancing of benefits and costs is likely sensitive to the cyclical state of the economy, and hence the generosity of benefits should also respond to the cyclical state of the economy. The nature of such responses in an optimal unemployment insurance program is analyzed in a simple model that balances the consumption smoothing benefits of unemployment insurance against the costs in terms of diminished labor market search and hence higher unemployment. The results suggest that an optimal UI program would increase the initial level of benefits and probably extend higher benefits over time in response to a recessionary shock. A simple extension of benefits provides both poorer insurance and poorer incentives than the optimal program, and does so at a higher cost.

The importance of the analysis is several-fold. First, the balancing of the consumption smoothing aspect of unemployment insurance against the disincentives such insurance provides for labor market search and willingness to accept job offers lies at the center of most work on optimal unemployment insurance (UI). ${ }^{1}$ Hence, such a balancing is the natural place to begin an analysis of the dependence of optimal UI benefits on the cyclical state of the economy. In the United States, the current structure of the UI system contains triggers for the extension of emergency benefits. In practice, such triggers make the generosity of the UI system greater during periods of high unemployment, and this automatic feature of the U.S. system has tended to be amplified by discretionary implementation of emergency benefits during recessions. The optimality of such changes in generosity over the business cycle has not been modeled formally, and the analysis herein both fills the gap in qualitative results and presents a rough quantitative exercise

\footnotetext{
${ }^{1}$ For work on the consumption smoothing benefit of UI, see Gruber (1997). Important work on the disincentive effects of UI benefits in the United States includes Feldstein (1974), Meyer (1990), and Card and Levine (2000). Work illustrating how an optimal UI system balances these benefits and costs includes Baily (1978), Shavell and Weiss (1979), and Hopenhayn and Nicolini (1997). Acemoglu and Shimer (1999) provide one notable alternative motivation for UI. In their analysis, a UI program encourages risktaking, which raises the efficiency of the economy.
} 
that gauges the degree to which UI benefits should vary over the cycle. The quantitative results suggest that the degree of variation in benefits over the business cycle would need to be large in order to equate the welfare of job losers at different points of the business cycle.

The analysis is important for two other reasons. In the United States, congressional debate over "emergency" extension of (UI) benefits in response to the recently declared recession (National Bureau of Economic Research (2001)) focused almost exclusively on two factors: stimulus (aggregate demand management) and disincentive effects of higher benefits on labor market search, and hence negative effect on aggregate measures of unemployment (Goldreich (2001)). The insurance aspect of the UI program received far less attention. The analysis herein shows that higher benefits in recessions exacerbate the incentive problems created by a UI program, as feared in the popular commentary; however, the insurance aspect of the program is more valuable when job search is less productive - i.e., during recessions - and hence increased generosity is optimal.

In addition, the United States is relatively unusual in allowing the generosity of UI benefits to vary with the cyclical state of the economy: Canada's program contains similar elements, but most other OECD countries - while providing substantially more generous UI benefits than in the U.S. - do not vary the generosity of benefits with aggregate labor market conditions. The results herein suggest that a program with such cyclical variation achieves a higher level of welfare during periods of labor market stress and smoothes the level of welfare of the newly unemployed over time, by concentrating benefits during periods when search activity is less fruitful and lowering benefits when search activity is more likely to yield a job.

The economic forces generating the results are intuitive. Following a shock that lowers the productivity of search effort (e.g., some shock lowering the supply of jobs), an insurance program designed to maintain the present discounted value of the utility of the newly unemployed equal to the value for newly unemployed absent the shock (i.e., in steady state) would increase the initial level of benefits and probably lower benefits over time by a smaller amount. The increase in the initial level of benefits relative to the steady state reflects the lower probability of finding a job given any level of search effort 
after the negative shock; since the probability of finding a job is now lower, benefits are higher. The lower rate of decrease of benefits over time reflects the tradeoff between providing consumption insurance and inducing search effort by the unemployed: Since search is less productive after the shock but will become more productive as the recession wanes, and because optimal benefits fall with the duration of the unemployment spell solely in order to spur productive search, the pace at which benefits fall after a negative shock is smaller under an optimal insurance program.

Section 2 presents background information of the changes in UI benefits over the business cycle in the United States to motivate the discussion. Section 3 discusses the response of benefits to cyclical conditions in a simple two-period model, illustrating that benefits should be more generous when the labor market deteriorates. Section 4 provides a dynamic model and a simple quantitative analysis of the degree to which benefits should vary over the business cycle within the context of a repeated principal-agent problem. Section 5 considers the effect of different assumptions regarding how recessions affect the productivity of search and wages upon reemployment. Section 6 concludes.

\section{Background ${ }^{2}$}

In the United States, unemployment insurance was born during the Great Depression, and its form reflects, in part, the concerns of that era (Baicker, Goldin, and Katz (1998)). The Social Security Act of 1935 (Public Law 74-271) created the Federal-State Unemployment Compensation Program. Two main objectives were given: (1) an insurance goal - to provide temporary income to involuntarily unemployed workers; and (2) a stimulus goal - to stabilize the economy during recessions. The analysis herein focuses on the insurance aspect of UI.

The UI system consists of individual state-administered programs, which use diverse methods to determine UI eligibility. For the most part, three major factors are used: (1) recent employment and earnings history; (2) the ability to seek and accept suitable employment; and (3) certain disqualifications related to a claimant's most recent job separation or job-offer refusal. In general, weekly benefit amounts are set as a

\footnotetext{
${ }^{2}$ This section relies heavily on Committee on Ways and Means (2000) and O'Leary and Wandner (1997).
} 
fraction of the individual's average weekly wage. The weekly benefit amounts typically replace between 50 and 70 percent of the average weekly pretax wage up to some maximum level. Because of the maximum benefit level, the replacement rate tends to vary inversely with the claimant's average weekly pretax wage. As a result, the average replacement rate was only 35 percent in the fourth quarter of 1999. In the quantitative exercises below, the replacement rate is set at 60 percent, in the middle of the range across states for low-wage workers; this was done as the exercises were viewed as most relevant for the insurance provided to the low-wage group, but the nature of the results is little changed if a replacement rate near 35 percent is chosen.

The maximum duration of benefit receipt is 39 weeks. The "regular" programs usually provide up to 26 weeks. The Federal-State Extended Benefits Program, enacted in 1970, provides up to 13 additional weeks in states where unemployment rates are relatively high at benefit levels that are identical to those under the regular program. ${ }^{3}$ The nature of the extended benefits program makes the generosity of the UI system greater during recessions or periods of labor-market weakness. In practice, the cyclical sensitivity of the UI program has been even greater because of enactment of emergency extensions six times since 1958. In 1958 and 1961, emergency programs extending benefits for 13 weeks, as under the current automatic program, were implemented. During the recession of the mid-1970s (after the enactment of the permanent extended benefit program), extended benefits were available in every state, reflecting the severity of the recession. Two more emergency programs were enacted in January and March of 1975, adding a total of 26 more weeks of extended benefits (to a total potential duration of benefits of 65 weeks between March 1975 and March 1977). A less generous emergency extension followed in April 1977. By 1980 and 1981, the shifting political climate and dissatisfaction with the results of extended benefits led to a substantial curtailing of the program. However, the recession of 1982 led again to an emergency expansion of benefit duration. Another emergency extension of benefits occurred between November 1991 and February 1994, following the recession of the early 1990s. The Congress approved

\footnotetext{
${ }^{3}$ The triggers for automatic extension of benefits are complicated and are discussed in Committee on Ways and Means (2000).
} 
and the President signed legislation temporarily extending benefits once more in March 2002.

The U.S. system of extended benefits in cyclical downturns is relatively unusual: Canada's UI system contains similar elements, but most other OECD countries do not. The extension of benefits in recessions may be justified on insurance grounds (O'Leary and Wandner (1997)), but a formal analysis has not been undertaken. Moreover, popular debate and even input from economists have focused little on increased benefit levels, rather than extended duration, in response to a deteriorating labor market in the United States (with some small exceptions; see Krueger (2001)).

In fact, a common reaction to this research has been that other factors, such as low wages for workers upon reemployment (e.g., Hipple 1999), discourage search in recessions and hence UI benefits should be less generous at such times to encourage search. Other objections have focussed whether assumptions about the marginal productivity of search in recessions drive the results because of empirically unjustified assumptions regarding these magnitudes. The formal analysis in section 4 will consider the form of an optimal benefit schedule following a negative shock in the labor market and examine the sensitivity of the results to each of these concerns. The lack of a central focus in the debate and these objections highlight how the results, while very straightforward once developed below, have gone under-appreciated. First, a simple model will be developed in preparation for the numerical analysis in section 4 .

\section{Simple Analytics}

To begin, a two-period model illustrating the forces affecting the optimal response of UI benefits to a recession is examined. Consider the following environment. The preferences of an unemployed worker over consumption $(\mathrm{c}(\mathrm{t}))$ and search effort $(\mathrm{a}(\mathrm{t}))$ are given by Equation $1 \quad u(c(1))-a(1)+\beta E u(c(2))$, where $\mathrm{E}$ is the expectations operator, $0<\beta<1$, and $\mathrm{u}(\mathrm{c}(\mathrm{t}))$ is strictly increasing, twice differentiable, and strictly concave. Both consumption and search effort must be nonnegative. Employed workers receive wage w. The consumption good is non-storable, and 
the unemployed cannot borrow or lend, and have no assets. Hence, the consumption of the unemployed equals the unemployment benefit they receive from the UI agency.

The probability an unemployed worker finds employment (in the first period to begin the next period) is given by $\mathrm{p}(\mathrm{a}(1), \mathrm{r})$, where $\mathrm{r}$ is a state variable governing the tightness in the labor market. The probability of finding a job is increasing in search effort, and search effort is subject to diminishing returns (i.e., $\mathrm{p}_{\mathrm{a}}>0, \mathrm{p}_{\mathrm{aa}}<0$, where subscript denotes partial derivative). Lower values of $r$ imply that it is more difficult to find a job at any given level of effort (i.e., $\mathrm{p}_{\mathrm{r}}>0$ ).

Given these conditions, the unemployed worker chooses search effort to maximize the following objective (where $b(t)$ is the UI benefit in period $t$ )

Equation $2 u(b(1))-a(1)+\beta[p(a(1), r) u(w)+(1-p(a(1), r)) u(b(2))]$.

The optimal choice of search effort is therefore governed by

Equation $3 \quad \beta p_{a}(a(1), r)[u(w)-u(b(2))] \leq 1$,

with equality if a $>0$.

As a simple thought experiment, consider the effects on the unemployed worker of an adverse labor market shock. At unchanged benefit levels, the worsening in labor market prospects lowers utility. ${ }^{4}$ Therefore, a UI agency concerned with targeting some constant level of welfare for an unemployed worker would need to raise benefit levels in either period 1 or period 2. Raising benefits in period 1 has the advantage of not affecting the search efforts of the worker (equation 3), i.e., does not produce disincentives in the labor market. However, raising benefits in period 1 has an important disadvantage. A given level of utility is achieved at lower cost by providing benefits in both period 1 and 2 , because of both diminishing returns to consumption and the fact that a certain fraction of the unemployed will find a job before period 2, and hence not receive period 2 benefits. Therefore, a cost-minimizing UI agency would respond to an adverse labor market shock by increasing benefits in both periods 1 and 2 . With this intuition in hand, a slightly more complicated model is developed.

\footnotetext{
${ }^{4}$ This result comes from applying the envelope theorem to equation 2.
} 


\section{Dynamic Model and Quantitative Analysis}

A model more suitable to quantitative implementation and capable of considering alternative assumptions regarding the productivity of search in recessions and the response of wages upon reemployment to labor market weakness is considered. The model follows those presented in Shavell and Weiss (1979), Hopenhayn and Nicolini (1997), and Ljungqvist and Sargent (2001). The analysis follows Ljungqvist and Sargent (2001) most closely; the important modification is the introduction of a possibly timevarying state variable that governs the degree of tightness in the labor market, and hence can be varied to proxy for recessions (or booms). As discussed more fully below, alternative assumptions regarding the effect of this shock on the productivity of search and wages are also examined.

The preferences of an unemployed worker over sequences of consumption $(\mathrm{c}(\mathrm{t}))$ and search effort $(\mathrm{a}(\mathrm{t}))$ from the current period (period 1) over the indefinite horizon are given by

Equation $4 \quad E \sum_{t=1}^{\infty} \beta^{t-1}[u(c(t))-a(t)]$,

where $\mathrm{E}$ is the expectations operator, $0<\beta<1$, and $\mathrm{u}(\mathrm{c}(\mathrm{t}))$ is strictly increasing, twice differentiable, and strictly concave. Both consumption and search effort must be nonnegative. Employed workers receive wage w, which does not vary over time. Moreover, it will be assumed that the unemployment insurance agency has no interaction with employed workers, and hence cannot implement any policy that involves taxation of the previously unemployed after such individuals find employment. ${ }^{5}$ The consumption good is non-storable, and the unemployed cannot borrow or lend, and have no assets. Hence, the consumption of the unemployed equals the unemployment benefit they receive from the UI agency.

The probability an unemployed worker finds employment (in the current period to begin next period) is given by $\mathrm{p}(\mathrm{a}(\mathrm{t}), \mathrm{r}(\mathrm{t}))$. $\mathrm{R}(\mathrm{t})$ is a state variable governing the tightness

\footnotetext{
${ }^{5}$ As in Hopenhayn and Nicolini (1997). Such an assumption has the virtue of administrative simplicity and will imply that optimal benefits are less radically different from current UI programs, which involve simple benefit schedules, than the benefit and tax policy developed under the alternative assumption.
} 
in the labor market that follows a first-order deterministic process. Lower values of $r(t)$ make it more difficult to find a job at any given level of effort (i.e., $\mathrm{p}_{\mathrm{r}}>0$, where subscript denotes partial derivative) - i.e., correspond to recession-like periods. The probability of finding a job is increasing in search effort, and search effort is subject to diminishing returns (i.e., $\left.\mathrm{p}_{\mathrm{a}}>0, \mathrm{p}_{\mathrm{aa}}<0\right)$.

Under these assumptions, the value of current employment $V^{\mathrm{e}}$ equals the present discounted value of consuming the wage (and hence does not vary over time),

Equation $5 \quad V^{e}=\frac{u(w)}{1-\beta}$.

The value of unemployment $\mathrm{V}^{\mathrm{u}}(\mathrm{t}, \mathrm{r}(\mathrm{t}))$ depends on the entire sequence of benefits $(\mathrm{b}(\mathrm{t}))$ received by the worker, and this dependence is reflected in the dependence of $\mathrm{V}^{\mathrm{u}}$ on the time period directly $(\mathrm{t})$; for example, if the benefit sequence consists of an initially high benefit in period 1 and a low or no benefit in future periods, then $\mathrm{V}^{\mathrm{u}}$ will, all else equal, be higher in period 1 then in later periods. In addition, the value of unemployment depends on the tightness of the labor market $(r(t))$. The Bellman equation for the value of unemployment is

\section{Equation 6}

$V^{u}(t, r(t))=\max _{a(t)}\left(u(b(t))-a(t)+\beta\left[p(a(t), r(t)) V^{e}+(1-p(a(t), r(t))) V^{u}(t+1, r(t+1))\right]\right)$

The optimal choice of search effort is therefore governed by

Equation $7 \quad \beta p_{a}(a(t), r(t))\left[V^{e}-V^{u}(t+1, r(t+1))\right] \leq 1$,

with equality if $a>0$. If the UI agency cannot choose search effort for the workers, its decision regarding the optimal benefit sequence must respect the individual rationality constraint given by equation 7 .

The UI agency chooses a sequence of benefits for the unemployed worker to achieve a target level of utility $\mathrm{V}^{\mathrm{u}}(1)$ for the newly (i.e., period 1) unemployed; this target level is exogenously determined elsewhere (perhaps by the political process). The agency wishes to achieve this target level of benefits at minimum cost, and such a minimum cost sequence is termed the optimal UI program. Two cases can be imagined: a full information case in which the agency can choose the sequence of benefits and search 
effort levels (i.e., no enforceability problems), and an asymmetric information case in which the sequence of benefits and effort levels are consistent with the unemployed workers' desired search levels (i.e., consistent with equation 7). The full information case solves the cost minimization problem

\section{Equation 8}

$C\left[V^{u}(t, r(t)), r(t)\right]=\min _{b(t), a(t), V^{u}(t+1, r(t+1))}\left(b(t)+\beta(1-p(a(t), r(t))) C\left[V^{u}(t+1, r(t+1)), r(t+1)\right]\right)$

subject to the constraint

$$
V^{u}(t, r(t)) \leq u(b(t))-a(t)+\beta\left[p(a(t), r(t)) V^{e}+(1-p(a(t), r(t))) V^{u}(t+1, r(t+1))\right]
$$

where $\mathrm{V}^{\mathrm{u}}(1)$ is exogenously determined, and the cost function $\mathrm{C}[$.] depends upon the continuation value of unemployment provided by the UI agency to the unemployed worker $\mathrm{V}^{\mathrm{u}}(\mathrm{t}, \mathrm{r}(\mathrm{t}))$ and on the state of the labor market, $\mathrm{r}(\mathrm{t})$. Notice that the cost function depends upon the discounted present value of costs into the future, and that discounting takes into account the discount factor of consumers and the probability of unemployment continuing into future periods. The asymmetric information case solves the cost minimization problem

\section{Equation 9}

$C\left[V^{u}(t, r(t)), r(t)\right]=\min _{b(t), a(t), V^{u}(t+1, r(t+1))}\left(b(t)+\beta(1-p(a(t), r(t))) C\left[V^{u}(t+1, r(t+1)), r(t+1)\right]\right)$ subject to the constraints equation 7 and

$$
V^{u}(t, r(t)) \leq u(b(t))-a(t)+\beta\left[p(a(t), r(t)) V^{e}+(1-p(a(t), r(t))) V^{u}(t+1, r(t+1))\right]
$$

where the additional constraint (equation 7) reflects the incentives of the unemployed given the benefit stream. Assuming that the cost function is strictly convex in the 
promised continuation level of utility ${ }^{6}$, the solutions to these problems yield the results of Shavell and Weiss (1979) or Hopenhayn and Nicolini (1997) for steady-state policies:

Previous Result: $\quad$ In a steady state with constant labor market conditions $(r(t)=r), A$. the optimal UI scheme in the full information case delivers a constant benefit level $(\mathrm{b}(\mathrm{t})=\mathrm{b} \forall \mathrm{t})$ and proscribes a constant level of search effort $(\mathrm{a}(\mathrm{t})=\mathrm{a} \forall \mathrm{t})$; $\mathrm{B}$. This effort level is not incentive compatible, and hence the optimal UI program under asymmetric information delivers a weakly declining benefit sequence $(b(t+1) \leq$ $\mathrm{b}(\mathrm{t}) \forall \mathrm{t})$. The sequence is strictly declining if search effort is productive $\left(\mathrm{p}_{\mathrm{a}}>0\right)$.

Proof: $\quad$ See Shavell and Weiss (1979), Hopenhayn and Nicolini (1997), Ljungqvist and Sargent (2000), or the appendix.

The results under asymmetric information are intuitive. Because higher future benefit levels raise the value of being unemployed in the future, they lower search effort (equation 7). Hence, a given level of utility can be achieved at lower cost by having an initially high level of benefits which declines over time - thereby raising search effort and lowering the expected expenses on benefits (because the higher search effort raises the probability that the unemployed worker finds a job). Note that benefits decline over time in the asymmetric information case only when search effort is productive $\left(\mathrm{p}_{\mathrm{a}}>0\right)$; absent productive search, efficient insurance would smooth consumption over time through a constant benefit level.

In addition, our numerical analysis establishes the following result, along the lines of the intuition from section 3, regarding the response of initial benefit levels to labormarket weakness:

New Result:

In response to a deterioration in the labor market, the optimal program increases initial benefit levels and proscribes a sequence

\footnotetext{
${ }^{6}$ As discussed in Hopenhayn and Nicolini (1997) or Ljungqvist and Sargent (2000), the constraints on the minimization problems are nonlinear and need not define a convex set, and hence the conditions under which the cost function is convex are not easy to prove. This complication could be overcome by using lotteries to convexify the constraint set (following Phelan and Townsend (1991)). In similar problems, numerical analysis often shows that such lotteries are unnecessary, and hence this complication is ignored.
} 
of benefits that declines more slowly over time, assuming less productive search in a recession.

The intuition remains similar to section 3. At unchanged benefit levels, the worsening in labor market prospects lowers utility. Therefore, a UI agency concerned with targeting some constant level of welfare for an unemployed worker needs to raise benefit levels. To examine in greater detail the effects of adverse labor market shocks (e.g., recessions) on optimal policy and to compare such policies with the standard practice of extended benefits in the United States, a quantitative version of the model is calibrated and simulated.

The utility function is isoelastic $\left(\mathrm{u}(\mathrm{c})=\mathrm{c}^{1-\mathrm{s}} /(1-\mathrm{s})\right)$. The length of a model period is one week, and consequently the discount factor $\beta$ equals 0.999 . The level of the wage earned by employed workers (w) is set at 100; with isoelastic utility, this level is unimportant for the results (and the chosen value simply provides a convenient scale). The intertemporal elasticity of substitution is set at $2(\mathrm{~s}=0.5)$. This high value is justified by the weekly frequency of the model period and matches the baseline value of Hopenhayn and Nicolini (1997). Lower values of this parameter do not change the qualitative results. $^{7}$

Regarding the productivity of search, the specific functional form $\mathrm{p}(\mathrm{a}(\mathrm{t}), \mathrm{r}(\mathrm{t}))$ equal to $1-\mathrm{e}^{-\mathrm{a}(\mathrm{t}) \mathrm{r}(\mathrm{t})}$ is assumed for the baseline results; this is the same form as used in Hopenhayn and Nicolini (1997) or Sargent and Ljungqvist (2000), except in those cases $\mathrm{r}(\mathrm{t})$ is held constant. Figure 1 graphs the probability of remaining unemployed (1$\mathrm{p}(\mathrm{a}(\mathrm{t}), \mathrm{r}(\mathrm{t})))$ for two illustrative values of $\mathrm{r}(\mathrm{t})$ - a tight labor market value and a weak labor market value. In the weak market, the probability of remaining unemployed is higher at any level of search effort (panel a). In the panel b (which is plotted on a log scale), it is shown that the semi-elasticity of the probability of remaining unemployed with respect to search effort - the slope of the line in the lower panel - is more negative in a tight labor market under the assumed functional form; this seems like the natural assumption, as it implies an increase in effort has a greater (in absolute value, i.e. more negative)

\footnotetext{
${ }^{7}$ Hopenhayn and Nicolini (1997) provide some illustrative simulations. Note that in the model, with no avenue for savings by workers, the intertemporal elasticity of substitution must be greater than one or period utility is not defined
} 
percentage effect on the probability of remaining unemployed in a tight labor market i.e., search is more productive in a boom. With regard to plausibility, it is important to note that this assumption does not imply that additional search has a larger effect on the probability of finding a job in a boom than in a recession. For example, it is plausible additional search has only a small effect on the probability of finding a job in a very tight labor market where, for example, the probability of finding a job at a given level of search is close to one. In a weaker labor market, extra search may have a larger marginal impact on the probability of finding a job. These effects are consistent with the assumed probability function, which implies that the percent change in the probability of remaining unemployed from an additional unit of search is larger in a boom. Because the probability of remaining unemployed in a tight labor market is smaller at any given level of effort, the percent change in this probability can be larger than in a recession even if the level change is smaller. However, the functional form and assigned parameter values will imply that, in the region of equilibrium search effort, additional search is more productive (in level terms, not only percentage terms) in a strong labor market. ${ }^{8}$ Section 5 discusses this more thoroughly.

Finally, the process for the state of the labor market is given by $r(t)=0.97^{t-1} r(1)+$ $\left(1-0.97^{t-1}\right) r^{*}$. The steady-state value of labor market conditions $\left(r^{*}\right)$ is chosen such that the steady-state median duration of unemployment (i.e., the value when $r(1)=r^{*}$ ) equals 7 weeks, the median value of median duration over 1967-2001 in the U.S. (and hence r* equals 0.00175 ). For this calculation, median duration is found by solving equation 7 given the current U.S. UI system, which is characterized by 26 weeks of benefits equal to 60 percent of the weekly wage - a value appropriate for low wage workers as discussed in section 2. For the recession scenario, the initial state of the labor market is chosen such that the median duration of unemployment rises to 9 weeks under the current U.S. system without extended benefits (yielding r(1) equal to 0.0015); such a value represents the edge of the upper 20 percent band in the histogram of median unemployment duration since 1967, and hence could be viewed as a modest recession.

\footnotetext{
${ }^{8}$ The qualifications to this statement, notably that it is true in the region of equilibrium search effort for the assigned parameter values, are necessary because additional search cannot be more productive in level
} 
Table 1 and the accompanying figures present the information on the costs and benefits of different UI programs, both in the steady state and in the recession scenario. The upper portion of table 1 presents information on the current U.S. UI system (with 26 weeks of benefits at a replacement rate of 60 percent) and the optimal system that delivers the same level of utility, both in steady state. The first row presents the benefit from each system, in units of consumption, relative to the current system in steady state; note that the benefit is equal by construction. The second row presents the expected annuity cost of each system as a percent of the weekly wage (i.e., $100 *(1-\beta) *$ $\left.\mathrm{C}\left[\mathrm{V}^{\mathrm{u}}(1), \mathrm{r}^{*}\right] / \mathrm{w}\right)$. The optimal program, which initially has a higher replacement rate than the current program (figure 2), delivers modest cost savings (around 6 to 7 percent, as found for somewhat different parameter values in Hopenhayn and Nicolini (1997)). The third column reports the median duration of unemployment under each program; for the current system and the optimal program, these median durations are quite similar in steady-state labor market conditions. The final column reports the average duration of unemployment. The optimal program shaves one week off the average duration of unemployment, reflecting the incentives to find a job provided by the falling schedule of benefits shown in figure $2 .{ }^{9}$ Overall, these results are in line with the previous literature.

The departure from previous work lies in the recession scenarios, provided in the bottom rows of table 1 . Row 3 shows the effects of the current system absent extended benefits. By construction, median and average unemployment duration are much higher in this scenario (columns C and D). Moreover, the cost of UI (column B) is much higher in the recession (about 0.60 percent of the base wage in annuity terms, rather than 0.49 percent in steady state) and lifetime utility (column A) falls by 0.8 percent of consumption (in perpetuity). A 13-week extension of benefits is shown in row 4: Such an extension raises utility modestly, raises costs per unemployed worker by more than 16 percent, and increases the average duration of unemployment by 1.45 weeks. Note that

terms for all possible values of effort in either a weak or strong labor market if the probability values are to remain bounded between zero and one and effort levels are not bounded from above.

${ }^{9}$ The calibration matches the median duration of unemployment in the data, but substantially underpredicts the mean duration. This could be because the data count as unemployed some workers with very little search activity or who are only very marginally attached to the labor force. Alternatively, the data may understate the median for the converse of the above reasons. Alternative parameterizations do not change the interesting results. 
this last figure - an increase of 0.1 week in average duration per extra week of benefits lies within the range of available estimates of the disincentive effects of the U.S. UI program, suggesting the calibration is reasonable. ${ }^{10}$

Rows 5 to 7 of table 1 provide information on optimally designed UI programs that meet different criteria. Row 5 presents a program that has the same expected cost per unemployed worker as the extended benefit program (EB) - 70 cents per $\$ 100$ in wages (column B). Such a program yields a small gain in utility relative to the EB program (in fact, so small that it is not apparent in the table). However, the incentives provided by the falling benefit schedule (shown in figure 3 with the extended benefit schedule) yield a substantially lower average duration of unemployment (column D); the average duration of unemployment is even lower than under the current system without EB (row 3, column D). Similarly, row 6 presents a UI program that delivers the same level of utility as the EB program, but does so at minimum cost. As shown in column B, the cost of an optimal program that delivers the same expected utility as the EB program is essentially the same as the current program without extended benefits (about 60 cents in a recession). This suggests policy debates regarding the expenditure consequences of more generous UI benefits in a recession are unnecessary, if such generosity is appropriately designed. In particular, the same level of utility as an EB program can be delivered by a benefit schedule with higher initial benefits that then decline over time (as shown in figure 4), without raising costs appreciably above those of the current system absent extended benefits. In sum, the current design of the U.S. UI program provides poorer insurance and poorer incentives than an optimally-designed program, and this weakness is particularly acute for the extended benefits portion of the U.S. system.

Figure 5 presents benefit schedules in different UI programs to illustrate how an optimally designed UI program responds to a recession; a log-scale is used to highlight both the level of benefits and the slope of the curves. The first schedule reported is the current 26-week benefit schedule with a replacement rate of 60 percent (the solid line). The second is the optimal program that delivers the same level of utility in steady state

\footnotetext{
${ }^{10}$ O'Leary and Wandner (1997) report a range of 0.1 to 0.5 for estimates for the increase in average unemployment duration associated with one extra week of benefits in the U.S., with most of the estimates lying closer to the bottom of that interval (see their table 7.1).
} 
(the dotted line). As noted previously, the optimal schedule has higher initial benefits that fall over time, as shown in Shavell and Weiss (1979) and Hopenhayn and Nicolini (1997). The third schedule is the optimal UI program that delivers the steady-state level of utility in a recession (the solid line with ${ }^{*}$ 's). Note that this schedule has a much higher level of benefits initially, and the benefits decline somewhat more slowly over time than the benefits in the optimal steady-state program. These results are intuitive in light of the model and the analytical results of section 3 and the proposition of this section. The higher level of benefits is necessary because the recession (lower $r(t)$ ) implies that workers will remain unemployed longer, and hence achieving the same level of utility requires higher benefits. The flatter slope of the benefit schedule occurs because the recession lowers the productivity of current search relative to that of future search (because the recession is transitory). Remember that falling benefits are only optimal to encourage search, and lowering the return to current search relative to future search lessens the importance of this role of declining benefits. Hence, the consumptionsmoothing role of UI assumes relatively more importance, and benefits decline more slowly in an optimal UI program during a recession.

Finally, the fourth (dotted with x's) line in figure 5 is the optimal benefit schedule that delivers the same utility as a EB program (i.e., row 6 of table 1). While utility is much lower than in the steady-state programs, this schedule shares the higher benefit level and flatter slope of the optimal program that delivers steady-state utility in a recession. This line is shown because providing the steady-state level of utility in a recession is very costly - about $\$ 1.85$ per $\$ 100$ in wages, versus the $\$ 0.61$ required to provide the utility of extended benefits (optimally) in a recession (row 6). This high cost occurs because recessions make search difficult; hence, the high level of benefits required to keep utility equal to steady-state utility is accompanied by a steep decline in search. Maintaining steady-state utility for newly unemployed workers in a recession yields a drastic increase in median and average unemployment duration to 17 weeks.

Two lessons are provided by these exercises. First, an optimal UI program has more generous benefits during recessions and a slower decline in benefits over time for any given target for unemployed workers' utility. In addition, recessions are periods of severe labor market stress. Hence, an optimally-designed UI program with similar cost to 
the current UI program in the U.S. would require sharply lower benefits during expansions and higher benefits during recessions, if the program wishes to deliver similar expected utility streams to newly unemployed workers. This occurs because jobs are easy to find during expansions and hard to find during recessions for any level of effort, and hence smoothing utility across booms and recessions requires low (high) benefits during booms (recessions). The current UI program delivers a high level of welfare to workers who lose jobs outside recessions - so high that the cost of delivering such a level of welfare during recessions is very large.

\section{Sensitivity Analysis}

Two sets of assumptions can be criticized as lacking support from previous empirical work. The first is the assumption that, in the region of equilibrium choices, search effort is more productive on the margin in a strong labor market, i.e. that in a strong labor market additional search has larger impact on the probability of finding a job. Introspection can suggest that this is a reasonable assumption, as it is possible that extra search in a recession yields little benefit (because, for example, an unemployed person's network of former employers and friends possess few potential openings and hence can provide little help if contacted). But, as mentioned earlier, the opposite is also possible, i.e. that in a very tight labor market, additional search is equally or more productive (because, for example, an unemployed person's network of former employers and friends are infrequently contacted by other potential applicants in such labor market conditions, and hence can provide significant help if contacted). The author's priors are that this possibility is less likely, but empirical evidence is unavailable, as the effect of labor market conditions on the marginal impact of search has not been a research priority (as with most cross-partial derivatives).

Sensitivity analysis demonstrates that the assumed impact of a recession on the marginal productivity of search is important. In particular, specifications in which the marginal productivity of search $\left(\mathrm{p}_{\mathrm{a}}\right)$ is independent of labor market conditions revealed that the optimal program of unemployment benefits would involve higher current and future benefits in a recession, but the slope of this benefit schedule was independent of 
labor market conditions. ${ }^{11}$ This result is intuitive. ${ }^{12}$ As discussed in section 4 , optimal benefits decline over time solely to induce desired search effort, and are constant when search is unproductive on the margin. In the case where the marginal productivity of search is not affected by labor market conditions, benefits must be higher in a recession to meet the desired level of welfare (since unemployment spells, as else equal, would tend to last longer), but the slope of the benefit schedule is unchanged as the marginal effects of search effort have not changed and these marginal effects determine the slope of the benefit schedule.

Another concern that has been offered as a reason why unemployment benefits should fall off more rapidly in a recession, rather than more slowly as in the baseline results, focuses on the effect of reemployment wages on search effort. It is well known that reemployment wages tend to be lower than wages from previous employment and evidence suggests this effect has been larger during recessions than during other periods (e.g., Hipple (1999)). Because unemployment benefits are based on past wages, the lower wages from reemployment discourage search effort (relative to a case where reemployment wages are not lower, as in the baseline model) (e.g., Feldstein and Poterba (1984)). If reemployment wages were lower during recessions than other periods, this effect would be magnified. Therefore, if one wanted to encourage job search during a recession, UI benefits should be lower than otherwise.

The approach taken herein delivers the opposite result - namely, lower reemployment wages should lead to more generous UI benefits. This occurs because the model assumes the program provides insurance and hence attempts to deliver a specified level of welfare to newly unemployed workers. If reemployment wages are lower, the

\footnotetext{
${ }^{11}$ The form of $\mathrm{p}(\mathrm{a}, \mathrm{r})$ used was $1-\mathrm{e}^{\mathrm{xa}}-\mathrm{r}$, where $\mathrm{x}$ is a constant. Higher values of $\mathrm{r}$ lower the probability of finding a job and hence correspond to weak labor market conditions, but do not affect the marginal productivity of search.

${ }^{12}$ While intuitive, the results were found using numerical examples; analytic results were not obtained. The results also suggested that this specification was qualitatively less capable of capturing basic intuition regarding the effects of changing labor market conditions. In particular, a worsening in labor market conditions under this specification tended to lower utility noticeably, and hence spur a significant additional amount of search. Because the productivity of search was not diminished by the shock and search rose, the expected duration of unemployment tended to actually fall, rather than rise, in response to the labor market deterioration. An alternative specification $(\mathrm{p}=1-[\mathrm{r} /(\mathrm{r}+\mathrm{a})])$ that could in theory imply that the marginal impact of search on the probability of finding employment was lower in a boom was also considered, but -
} 
(present discounted value of) welfare of the unemployed is lower, and hence an insurance policy offers higher benefits to those who enter unemployment during recessions. This will tend to lengthen the unemployment spell of the newly unemployed, but such leisure is simply part of the bundle of benefits provided by UI to ensure a given target level of welfare. The suggestion that UI benefits should be less generous and shortened to encourage extra search lowers welfare and would exacerbate the large gap in the level of welfare delivered by UI between recessions and other periods discussed in section 4 .

\section{Conclusion}

The results suggest that an optimal UI program would increase the initial level of benefits and probably extend higher benefits over time in response to a recessionary shock. A simple extension of benefits provides both poorer insurance and poorer incentives than the optimal program, and does so at a higher cost. Moreover, the quantitative exercise suggests that the current UI program in the United States provides substantially higher welfare to workers who lose jobs during tight labor markets, in the sense that delivering such a level of welfare to workers who become unemployed during recessions would require very generous benefit levels. To the extent that simple models like that herein can be used to guide policy (and in the author's view that extent is important but not overwhelming), the results of this investigation suggests that reform of the UI program should lower benefits substantially during tight labor markets and raise benefits during weak labor markets, and should consider a schedule in which benefits fall with duration as suggested in previous work. More simply, increased early generosity of benefits in recessions is superior to extended benefits in providing insurance and incentives.

Several important aspects of the analysis deserve further scrutiny. The first is the information requirements of time-varying benefit schemes. In this analysis, the UI agency had access to information on the state of the labor market (i.e., a current recession). In application, long unemployment spells could reflect either the state of the labor market or weak search activity. The feasibility of time-varying benefit schemes in an environment where it is difficult to discern the state of the labor market from endogenous variables

like the baseline case - this specification implied that the marginal impact of search on the probability of 
like unemployment duration deserves further research effort. In addition, some simplifying assumptions could be relaxed, such as the assumption that unemployed workers have no savings or access to credit markets. While such simplifying assumptions may be reasonable as a first step, especially for describing the behavior of very lowincome households, the more complex analysis required by adding asset accumulation could prove fruitful. ${ }^{13}$ Moreover, the analysis was decidedly partial equilibrium in nature, and abstracted from the financing of the UI program. Given that a program could be designed with cyclical variation in benefits that had similar cost to the current program (over a business cycle) and that had a (relatively) smooth path of taxes (which may be optimal for traditional reasons), financing issues may have little effect on the results herein.

finding employment was higher in a boom for reasonable parameter values and at equilibrium search levels. ${ }^{13}$ In this regard, recent work by Abdulkadiroglu, Kuruscu and Sahin (2001) and Werner (2001) show the complications such an addition can generate and provide some tools to help future analyses. 


\section{References}

Abdulkadiroglu, Atila, Burhanettin Kuruscu and Aysegul Sahin (2001) Unemployment Insurance and the Role of Self-Insurance. Forthcoming in the Review of Economic Dynamics.

Acemoglu, Daron and Robert Shimer (1999) Efficient Unemployment Insurance. Journal-of-Political-Economy 107(5), October, pages 893-928.

Baicker, Katherine, Claudia Goldin and Lawrence F. Katz (1998) A Distinctive System: Origins and Impact of U.S. Unemployment Compensation. In Bordo, Michael D., Claudia Goldin and Eugene White, eds. The defining moment: The Great Depression and the American economy in the twentieth century. University of Chicago Press, NBER Project Report series, Chicago and London, pages 227-63. Baily, Martin Neil (1978) Some Aspects of Optimal Unemployment Insurance. Journalof-Public-Economics 10(3), December, pages 379-402.

Card, David and Phillip B. Levine (2000) Extended Benefits and the Duration of UI Spells: Evidence from the New Jersey Extended Benefit Program. Journal-ofPublic-Economics 78(1-2), October, pages 107-38.

Committee on Way and Means (2000) The 2000 Green Book Background Material and Data on Programs within the Jurisdiction of the Committee on Ways and Means. U.S. House of Representatives, October 6, 17th edition http://aspe.hhs.gov/search/2000gb/2000gb/index.htm\#toc.

Feldstein, Martin S. (1974) Unemployment Compensation: Adverse Incentives and Distributional Anomalies. National-Tax-Journal 27(2), June, pages 231-44.

Feldstein, Martin S. and James Poterba (1984) Unemployment Insurance and Reservation Wages. Journal-of-Public-Economics 23(1-2), February-March, pages 141-67.

Goldreich, Samuel (2001) Social Issues Resurface in Jobless Debate. CQ Weekly 59(41), October 27, pages 2524-2525.

Gruber, Jonathan (1997) The Consumption Smoothing Benefits of Unemployment Insurance. American-Economic-Review 87(1), March, pages 192-205.

Hipple, Steven (1999) Worker Displacement in the Mid-1990s. Monthly-Labor-Review 122(7), July, pages 15-32. 
Hopenhayn, Hugo A. and Juan-Pablo Nicolini (1997) Optimal Unemployment Insurance. Journal-of-Political-Economy 105(2), April, pages 412-38.

Krueger, Alan B. (2001) Economic Scene; The stimulus package should fix the unemployment insurance program first. The New York Times, October 18.

Ljungqvist, Lars and Thomas J. Sargent (2000) Recursive Macroeconomic Theory. MIT Press, Cambridge, MA.

Meyer, Bruce D. (1990) Unemployment Insurance and Unemployment Spells. Econometrica 58(4), July, pages 757-82.

National Bureau of Economic Research (2001) The Business-Cycle Peak of March 2001. November 26.

Organisation for Economic Co-operation and Development (OECD) (1997) Implementing the OECD jobs strategy : lessons from member countries' experience. OECD, Paris.

O'Leary, Christopher J. and Stephen A. Wandner, eds. (1997) Unemployment Insurance in the United States: Analysis of Policy Issues. W. E. Upjohn Institute for Employment Research, Kalamazoo, MI.

Phelan, Christopher and Robert M. Townsend (1991) Computing Multi-period, Information-Constrained Optima. Review-of-Economic-Studies 58(5), October, pages $853-81$.

Shavell, Steven and Laurence Weiss (1979) The Optimal Payment of Unemployment Insurance Benefits over Time. Journal-of-Political-Economy 87(6), December, pages 1347-62.

Werning, Ivan (2001) Optimal Unemployment Insurance with Unobservable Wealth. Mimeo, University of Chicago. 


\section{Appendix: Proof previous results}

The proof of proposition 1 follows that in Sargent and Ljungqvist (2000) for the same problem. The first-order conditions for the full information problem are

\section{A1}

$$
\theta=\frac{1}{u_{c}(b(t))}
$$

A2 $C\left[V^{u}(t+1, r(t+1)), r(t+1)\right]=\theta\left[\frac{1}{\beta p_{a}(a(t), r(t))}-\left(V^{e}-V^{u}(t+1, r(t+1))\right)\right]$, A3

$$
C_{V}\left[V^{u}(t+1, r(t+1)), r(t+1)\right]=\theta,
$$

where $\theta$ is the multiplier on the constraint. The envelope theorem implies

A4

$$
C_{V}\left[V^{u}(t, r(t)), r(t)\right]=\theta,
$$

which implies that $\mathrm{V}^{\mathrm{u}}$ is constant over time for a constant value of $\mathrm{r}$ (using A3). Hence, consumption and effort of the unemployed are constant over time in a steady state, as in part A of the proposition.

The first-order conditions for the asymmetric information problem are (assuming $a(t)>0$, so equation 7 binds)

A5

$$
\theta=\frac{1}{u_{c}(b(t))}
$$

A6

$$
C\left[V^{u}(t+1, r(t+1)), r(t+1)\right]=-\eta\left[\frac{p_{a a}(a(t), r(t))}{p_{a}(a(t), r(t))}\left(V^{e}-V^{u}(t+1, r(t+1))\right)\right],
$$

$$
C_{V}\left[V^{u}(t+1, r(t+1)), r(t+1)\right]=\theta-\eta\left[\frac{p_{a}(a(t), r(t))}{1-p(a(t), r(t))}\right],
$$

where $\theta$ is the multiplier on the second constraint. The envelope theorem implies

A8

$$
C_{V}\left[V^{u}(t, r(t)), r(t)\right]=\theta .
$$

A6 and the assumptions regarding $p($.$) ensure that \eta$ (the multiplier on equation 7 ) is positive. Therefore, $\mathrm{A} 8$ and $\mathrm{A} 7$ ensure that $\mathrm{V}^{\mathrm{u}}$ falls over time for a constant value of $\mathrm{r}$ (because C[.] is convex). A5 and A8 then imply that the benefit sequence must fall over time. Also, if $\mathrm{p}_{\mathrm{a}}=0, \mathrm{~A} 7$ and $\mathrm{A} 8$ imply constant benefits over time, concluding part $\mathrm{b}$ of the proposition. 


\begin{tabular}{|c|c|c|c|c|}
\hline & $\begin{array}{c}\text { A } \\
\text { Relative } \\
\text { benefit of } \\
\text { program in } \\
\text { consumption } \\
\text { units (percent) }\end{array}$ & $\begin{array}{c}\text { Annuity cost } \\
\text { of program as } \\
\text { percent of } \\
\text { weekly wage }\end{array}$ & $\begin{array}{c}\text { Median } \\
\text { duration of } \\
\text { unemployment } \\
\text { (weeks) }\end{array}$ & $\begin{array}{c}\text { Average } \\
\text { duration of } \\
\text { unemployment } \\
\text { (weeks) }\end{array}$ \\
\hline \multicolumn{5}{|c|}{ Steady-State (SS) Labor Market Conditions } \\
\hline 1. Current Program & 100.0 & 0.49 & 7.0 & 8.29 \\
\hline 2. Optimal Program & 100.0 & 0.46 & 7.0 & 7.28 \\
\hline \multicolumn{5}{|c|}{ Recession Conditions in Labor Market } \\
\hline 3. Current Program & 99.2 & 0.60 & 9.0 & 10.35 \\
\hline $\begin{array}{l}\text { 4. Current Program with } \\
\text { Extended Benefits (EB) }\end{array}$ & 99.3 & 0.70 & 10.0 & 11.80 \\
\hline $\begin{array}{l}\text { 5. Optimal Program when cost } \\
\text { equals EB cost }\end{array}$ & 99.3 & 0.70 & 9.0 & 10.12 \\
\hline $\begin{array}{l}\text { 6. Optimal Program when utility } \\
\text { equals EB utility }\end{array}$ & 99.3 & 0.61 & 9.0 & 9.48 \\
\hline $\begin{array}{l}\text { 7. Optimal Program when utility } \\
\text { equals SS utility }\end{array}$ & 100.0 & 1.85 & 17.0 & 17.94 \\
\hline
\end{tabular}


Figure 1

Panel A: Probability of remaining unemployed in different labor markets

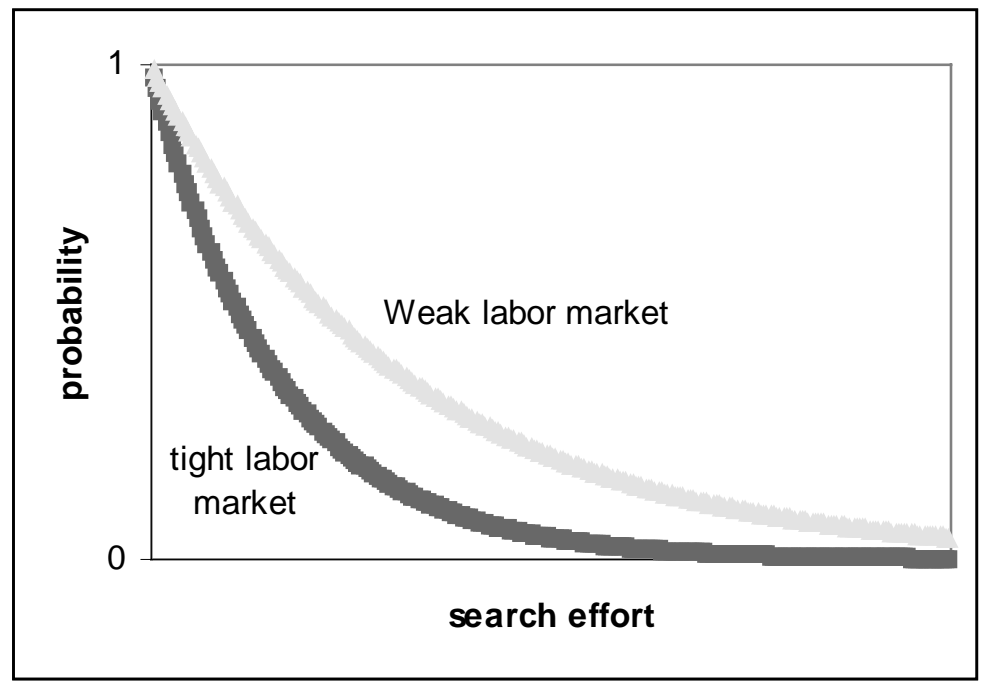

Panel B: Semi-elasticity (slope of lines) of probability of remaining unemployed in different labor markets

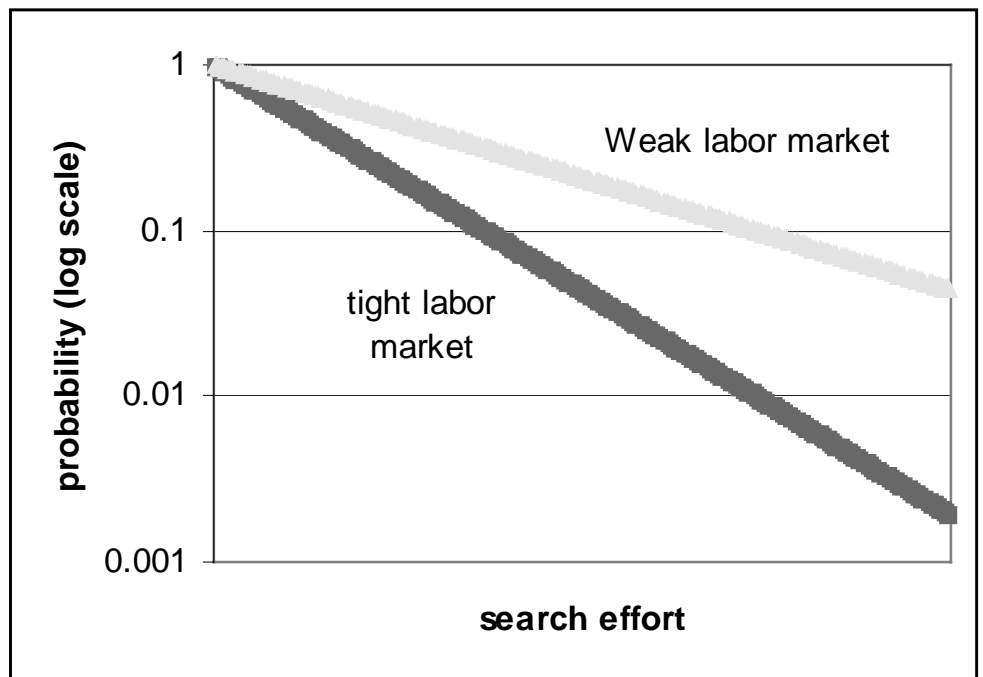


Figure 2: Benefits in Current Program and Optimal Program (steady-state labor market)

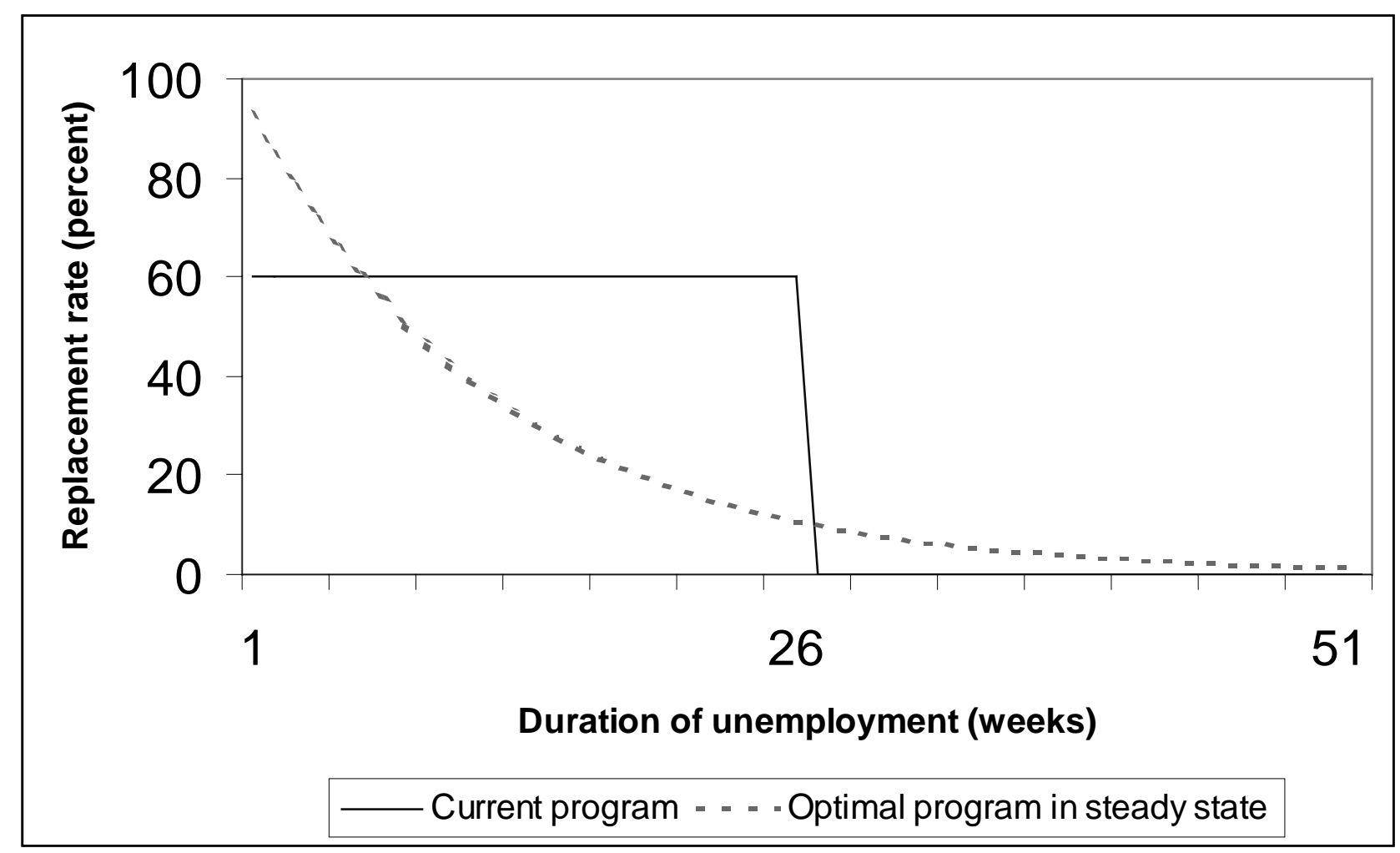

Notes: Expected utilities for a newly unemployed worker is equal under each program 
Figure 3: Benefits in Extended Benefits Program and Optimal Program with identical cost (recessionary labor market)

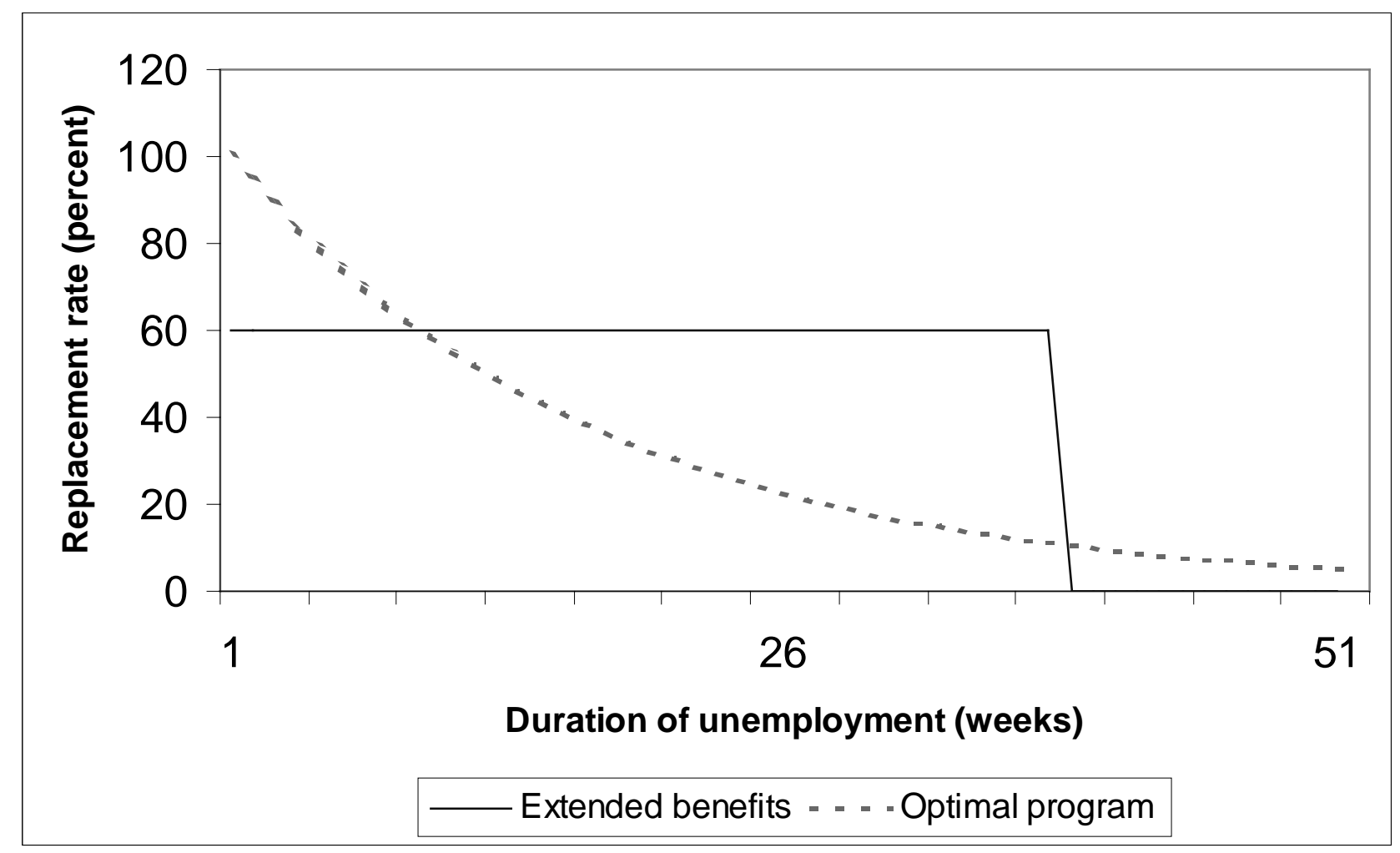


Figure 4: Benefits in Extended Benefits Program and Optimal Program with identical utility (recessionary labor market)

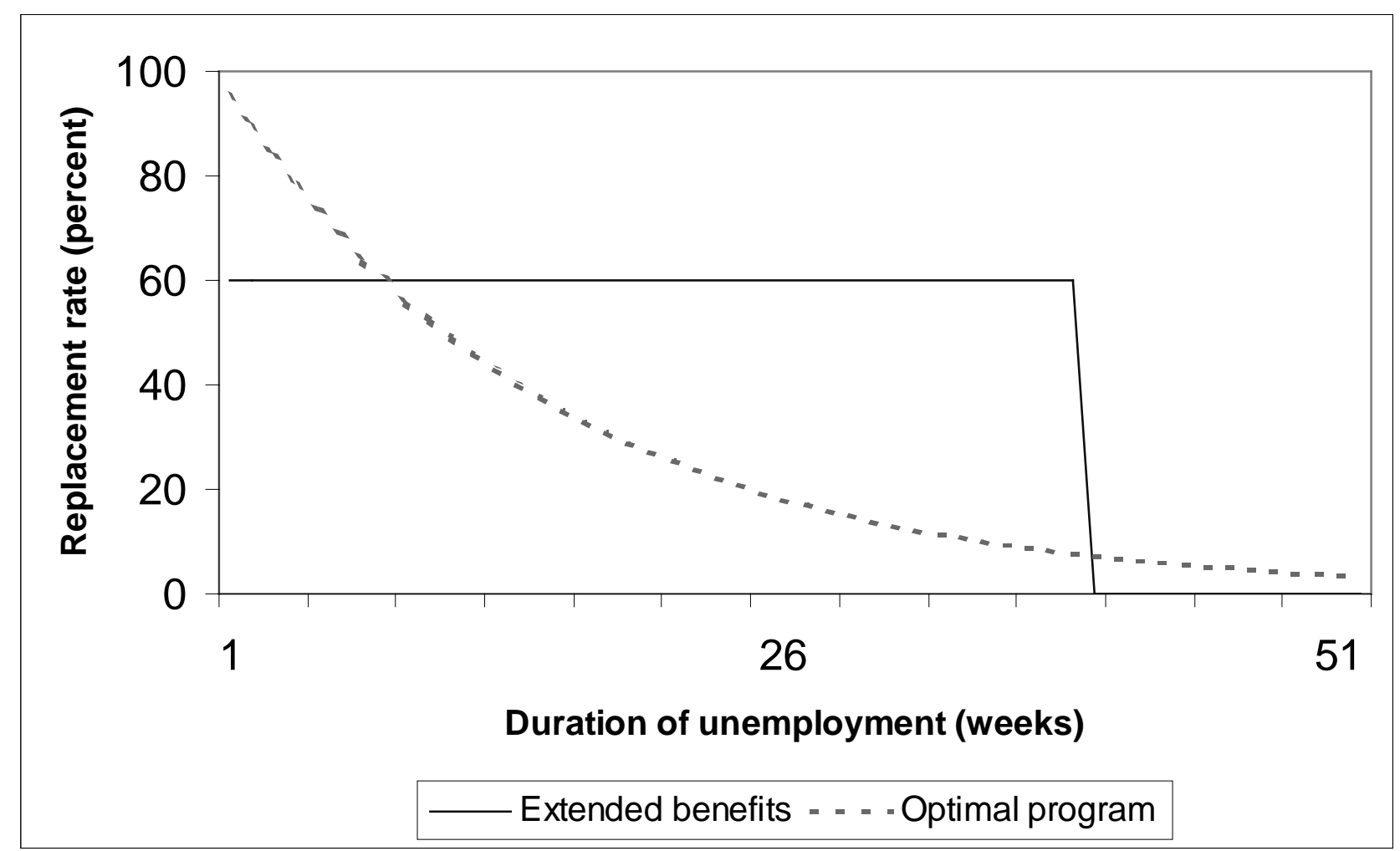


Figure 5: A Comparison of Alternative Programs

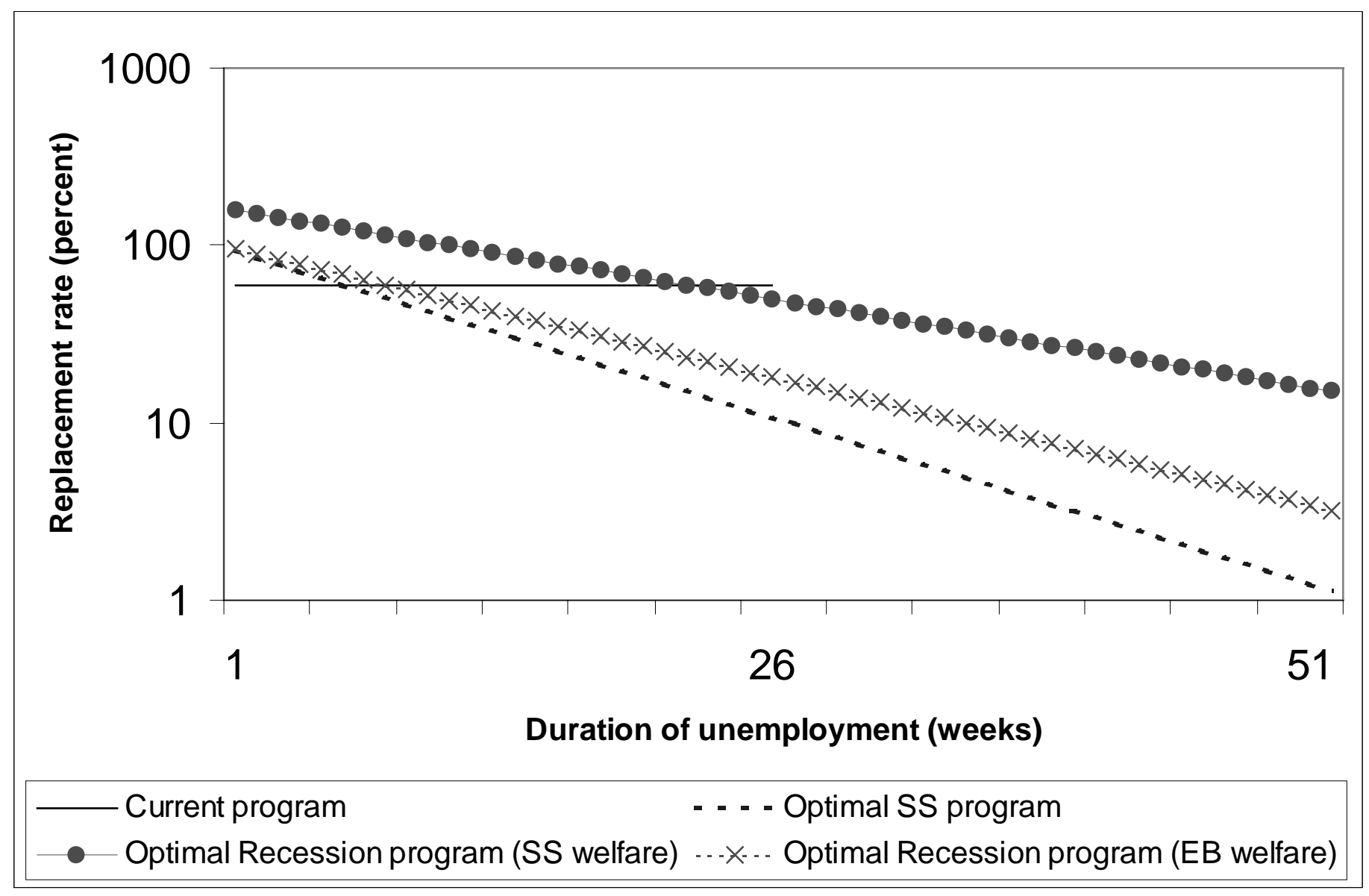

